\title{
ACESSIBILIDADE: CONCEITOS E FORMAS DE GARANTIA
}

\author{
Priscila Moreira CORRÊA ${ }^{1}$
}

FERNANDES, Edicléa Mascarenhas; ORRICO, Hélio Ferreira. A cessibilidade e inclusão social. Rio de Janeiro: Deescubra, 2008.

Com a valorização e reconhecimento da convivência com a diversidade, o termo acessibilidade tem sido utilizado para garantir que todas as pessoas tenham acesso a todas as áreas de seu convívio. Estas áreas estão relacionadas aos espaços, mobiliários, equipamentos urbanos, sistemas e meios de comunicação e informação. Desta forma, espera-se que haja uma preparação e uma resposta às necessidades especiais que esta diversidade pode apresentar nestas áreas.

Neste contexto, os autores do livro A cessibilidade e inclusão social apresentam o termo acessibilidade como palavra que pode expressar possibilidades, alcance de objetivos, cumprimento de metas ejustiça social. Neste livro, podemos encontrar diferentes discussões que englobam análises sobre a elaboração e execução das leis sobre acessibilidade e sobre as formas de garantir a acessi bilidade para todas as pessoas nos campos da Educação, Saúde, Trabal ho e Assistência Social.

Os autores deste livro são professores universitários e possuem experiência em diversos temas que estão rel acionados à inclusão social das pessoas com deficiência, como os temas Políticas Públicas e A cessibilidade. O livro surgiu a partir das palestras que foram ministradas pelos autores em diversos locais, como nas universidades, escolas, congressos, centros de saúde, associações de pessoas com deficiência, dentre outros.

A obra, constituída por cinco capítulos, apresenta um referencial teórico coerente em relação aos documentos legais sobre a garantia da acessibilidade e está disponível tanto em formato impresso quanto no digital, em CD.

No Capítulo I, é apresentada uma revisão de registros sobre a promoção da acessibilidadequeseiniciaram nos primórdios da existência humana. Neste capítulo, são contemplados os valores e atribuições em relação às pessoas

\footnotetext{
${ }_{1}^{1}$ Mestranda do Programa de Pós-graduação em Educação da Faculdade de Filosofia e Ciências da Unesp - campus de Marília - Bolsista FAPESP - priped@bol.com.br 
com deficiência em diferentes fases da humanidade. Apresenta tópicos sobre os antigos e atuais paradoxos em relação à exclusão/ inclusão destas pessoas. 0 capítulo ajuda o leitor a compreender a regularidade das formações discursivas para a promoção da acessibilidade em documentos da Idade Moderna e Contemporânea.

O Capítulo II apresenta como surgiram as políticas públicas destinadas às pessoas com deficiências ligadas às áreas da Educação, Saúde, Trabalho e Assistência Social. A presenta de que modo estas políticas se constituíram no contexto da sociedade brasileira e como se encontram atualmente.

Os documentos legais atuais que garantem a acessibilidade no Brasil são apresentados no Capítulo III. N esta apresentação, são definidos os conceitos de acessibilidade, barreiras arquitetônicas, barreiras arquitetônicas urbanísticas, barreiras comunicacionais e ajudas técnicas. Para que o leitor compreenda as rupturas existentes entre o texto da lei e as práticas efetivas da acessibilidade às pessoas com deficiência, são apresentadas neste capitulo anál ises de dois estudos.

No capítulo IV é analisado o cotidiano da inclusão social das pessoas com deficiência intelectual, deficiência auditiva, deficiência física, deficiência visual e autismo. São apresentados conceitos e concepções sobre os tipos de deficiência, os suportes e as formas de acessibilidade que devem ser oferecidos, as barreiras que podem ser encontradas, a inclusão destas pessoas na escola e como estas pessoas eram e são avaliadas.

O Capítulo V encerra a obra com uma discussão sobre a convergência entre as capacidades adaptativas referidas pela Associação Americana de Deficiência Intelectual e os pressupostos da Classificação Internacional de Funcionalidade.

Recomenda-se o livro para profissionais, familiares e estudantes de diversas áreas de conhecimentos que irão trabalhar com a acessibilidade. É uma boa leitura para compreender e analisar o tema acessibilidade. 